\title{
Rol del trabajador social como intelectual orgánico en la implementación de políticas sociales
}

\author{
The social worker's role as an organic intellectual in the \\ implementation of social policies
}

O papel do assistente social como um intelectual orgânico na implementação de políticas sociais

Carolina Álvarez Caro*

\section{RESUMEN}

El objetivo del artículo es plantear algunas reflexiones respecto Palabras clave: del actuar profesional de los trabajadores sociales, en virtud de los diferentes procesos históricos a los cuales se ha visto enfrentada la disciplina y que han ido moldeando su práctica. En este sentido, se puede mencionar que, como articuladores de los recursos del Estado, destinados a ciertos sectores de la sociedad civil, se han convertido en mantenedores y replicadores de la ideología de la clase dominante - hegemonía neoliberal-, con un marcado sesgo propio de la colonialidad. Surge la necesidad, entonces, de plantear un análisis desde el pensamiento crítico, que permita a los profesionales cuestionar su labor como agentes de cambio.

\begin{abstract}
The objective of this document is to raise some reflections on the professional actions of Social Workers, according to the different historical processes seen by the discipline and which have been shaping its practice. In this sense, as coordinators of government resources assigned to certain sectors of civil society, it can be said that they have become supporters and replicators of the ideology of the ruling class, a neoliberal hegemony with a marked bias
\end{abstract} Key words: quehacer profesional, intelectual orgánico, hegemonía neoliberal, colonialidad, pensamiento crítico. Professional work, organic intellectual, neoliberal hegemony, 
characteristic of coloniality. In this way, there needs to be analysis based on critical thinking that allows professionals to question their work as agents of change.

\section{RESUMO}

O objetivo do artigo é levantar algumas reflexões a respeito da atuação profissional dos assistentes sociais, em virtude dos diferentes processos históricos que a disciplina vem enfrentando e que moldaram sua prática. Neste sentido, é possível mencionar que, como articuladores dos recursos do Estado, destinados a determinados setores da sociedade civil, tornaram-se mantenedores e replicadores da ideologia da classe dominante - hegemonia neoliberal -, com um acentuado viés próprio da colonialidade. Surge, então, a necessidade de propor uma análise, a partir da perspectiva do pensamento crítico, que permita aos profissionais questionar seu trabalho como agentes de mudança. coloniality, critical thinking.

Palavraschave: trabalho profissional, intelectual orgânico, hegemonia neoliberal, colonialidade, pensamento crítico. 


\section{Introducción}

El presente ensayo tiene por objetivo problematizar el quehacer profesional del trabajador social, en su ámbito de intervención y operacionalización de políticas sociales. Lo anterior se hace posible a partir de un análisis reflexivo, teniendo como base la propia experiencia profesional, articulado esto con los referentes teóricos que permiten hacer una síntesis dialéctica de esta relación teoría/práctica. En relación con esto, surgen una serie de reflexiones acerca de las gestiones-intervenciones de los profesionales que, por lo general, se encuentran situadas desde contextos institucionales (ONG, Fundaciones, entre otros), que están hegemonizados por una racionalidad tecno-instrumental y economicista, ya sean entidades propias del Estado o ejecutoras de su labor por medio de subvenciones. Este contexto, y la experiencia subjetiva en tanto conciencia histórica (Gramsci, 2012, 2017), nos permite sostener que la racionalidad neoliberal se ha transformado en hegemónica, y que los profesionales han caído en una especie de alienación que genera intervenciones instrumentales, poco reflexivas, transformando su quehacer en un rol, en una función de intelectual tributario de los intereses de las elites dominantes (Gramsci, 2006, 2012, 2017; Vivero, 2013, 2017a, 2017b, 2020b).

Esta racionalidad neoliberal (Brown, 2015), impuesta en Chile en un contexto de dictadura cívico-militar, ha entregado al sector privado la provisión de servicios sociales, por medio de subvenciones o tercerización que, en definitiva, se ha traducido en mercantilizar la política social. Estas instituciones o entidades colaboradoras (principalmente en el ámbito de la infancia y adolescencia), por definición deben ceñirse a la política pública en desarrollo, independiente del conglomerado político que se encuentre asumiendo la administración del país. En tal sentido, los gobiernos posdictadura no han hecho más que administrar el modelo de sociedad impuesto en el régimen de facto.

Es importante mencionar que la sociedad en su conjunto ha sido permeabilizada por la concepción de mundo neoliberal (Brown, 2015) y, por lo tanto, las/os trabajadores sociales no están ajenos a ello, sino que, en tanto intelectuales orgánicos (Vivero, 2013), en sus acciones profesionales contribuyen a su preproducción. Los trabajadores sociales, consciente o inconscientemente, han asumido un rol de intelectuales orgánicos, replicando y validando la ideología de la clase do- 
minante, y manteniendo y sosteniendo dinámicas de desigualdad de clases, amparados por la ejecución de políticas públicas (Vivero, 2013, 2017a).

En virtud de esta influencia ideológica, se ha constituido en un nuevo sentido común (Gramsci, 2006, 2012, 2017; Vivero, 2013, 2020b). Podemos encontrar profesionales escasamente cuestionadores, con un pensamiento marcado por los saberes europeos y norteamericanos, pensamiento más bien positivista que no admite otras realidades o cosmovisiones, y que transmite, en su acción cotidiana, representaciones europeas de lo "adecuado o aceptado" (Vivero, 2017b). De esta neocolonización del saber y del poder encontramos diversos ejemplos en los discursos y acciones profesionales, que se materializan en definiciones conservadoras de "familia" y "relaciones sociales", en dicotomías entre lo femenino y masculino, entre tantos otros temas que impiden desplegar sus propios conocimientos y saberes a las personas sujetos de la intervención.

En consecuencia, postulamos que un ejercicio profesional que no se articule desde una concepción crítica, desde una síntesis dialéctica teoría/práctica, contribuye de forma mecánica y alienada a la reproducción de la racionalidad neoliberal, en tanto que, como profesional e intelectual de las ciencias sociales, juega un rol de intelectual orgánico. Por lo mismo, concordamos con Vivero (2017a, 2017b, 2020a) respecto de que se requiere repensar críticamente el trabajo social, para avanzar en un proceso de redefinición epistemológica y política que sustente un nuevo tipo de trabajo social, con perspectiva latinoamericana.

\section{El neoliberalismo en Chile y su influencia en el Trabajo Social}

Como se mencionó en la introducción, el neoliberalismo se impone en Chile en un contexto sociopolítico caracterizado por una dictadura cívico-militar. La dictadura y los economistas, conocidos como "Chicago Boys", imponen un modelo económico y político que Moulian (1997) denomina "proyecto modernizador contrarrevolucionario". En este sentido, como señala Vivero (2017b), este modelo también ha influido en todos los campos de las ciencias sociales y, por supuesto, en el quehacer y la formación del Trabajo Social. 
El contexto histórico que permite la imposición de esta ideología se genera con el golpe de Estado del 11 de septiembre de 1973, caracterizado por graves violaciones a los derechos humanos y con una dictadura de 17 años que culmina con el triunfo del "No" y posterior elección democrática de Patricio Aylwin Azócar, con lo cual se da inicio a la transición en marzo de 1990.

Durante el periodo que comprende la dictadura, el campo de Trabajo Social sufre un significativo retroceso respecto de todo aquello que había logrado con el movimiento de "reconceptualización" (Vivero, 2017a). Entre otros aspectos, este retroceso se caracteriza por imponer una formación conservadora, sustentda en perspectivas que reproducen formas de intervención de carácter asistencialista y tecnocrático, las cuales se habían dado por superadas hasta antes del golpe de Estado (Vivero, 2017a). En la misma línea, se puede afirmar que el neoliberalismo se instaura ya no solo como un modelo económico más, sino como una corriente ideológica que se expresa en las distintas formas de construcción de las ideas. De este modo, se producen cambios importantes en las diferentes estructuras de la sociedad civil, ya que se comienza a perder los valores comunitarios y de bienestar social, consolidándose los de consumo y propiedad, primando la satisfacción de las necesidades individuales.

Respecto de lo anterior, se han establecido nuevas necesidades y satisfactores de estas, focalizando todas las acciones en torno a los individuos, lo cual trae como contraparte que el sujeto sea responsable de su propio bienestar y gestor de sus procesos; por lo tanto, en términos de lo planteado por Gramsci $(2006,2012,2017)$, se ha instalado un nuevo sentido común que se materializa en el individualismo extremo. De este modo, el contexto histórico-político surge como una expresión de la hegemonía de una cierta ideología y ello permite la configuración de un contexto que, entre otras cuestiones, se expresa en una mayor desigualdad y exclusión social. Ello favorece la mantención de brechas y desigualdades entre los diferentes actores y estamentos de la sociedad civil, por lo que estos procesos de instalación de una cierta ideología requieren de un proceso de transformación social y cultural (Gramsci, 2006, 2012).

En este ámbito, la hegemonía representa la supremacía lograda por la sociedad civil respecto de la sociedad política, en la cual la primera 
corresponde a la mayor parte de la superestructura, conformada por las "llamadas organizaciones privadas, como la Iglesia, los sindicatos, las escuelas, etc." (Gramsci, 2006, p.146). De esta forma, desde la clase dominante se establecen estrategias para reproducir y mantener esta ideología, en la cual los intelectuales orgánicos tienen un rol fundamental, ya que entregan los argumentos, así como las estrategias, para llegar a todos los estratos de la sociedad civil, entre las que podemos identificar la forma de estratificar la "pobreza", o que ya no hablemos de ella sino de "vulnerabilidades", o que nuestra denominación de "país del tercer mundo" se haya cambiado por "en vías de desarrollo", entre tantas otras.

\section{El concepto de "intelectual" y su expresión en el Trabajo Social}

En este trabajo hemos venido sosteniendo que el campo disciplinario ha sido fuertemente influido por los cambios sociohistóricos en Chile, generados fundamentalmente desde el golpe de Estado de 1973. En esa misma línea, la disciplina no solo ha sufrido un proceso de retroceso a concepciones conservadoras, especialmente en el campo de la intervención, sino que la producción y reproducción de esto es posible porque existen intelectuales que articulan ciertos saberes y prácticas en los diferentes espacios de las relaciones sociales y de producción (Gramsci, 2006, 2012, 2017). En esta discusión nos interesa conceptualizar la idea de "intelectual" a partir de lo que plantea Antonio Gramsci. $\mathrm{Al}$ respecto, señala que

Todo grupo social, como nace en el terreno originario de una función esencial en el mundo de la producción económica, se crea al mismo tiempo y orgánicamente una o más capas de intelectuales que le dan homogeneidad y consciencia de su propia función, no solo en el campo económico, sino también el social y político. (Gramsci, 2017, p. 388)

En la misma línea, el autor agrega que los grupos sociales nacen en un contexto histórico determinado y, por lo tanto, encuentra tipos de intelectuales preexistentes que parecen "representar una continuidad histórica ininterrumpida, a pesar de los cambios más complicados y radicales de las formas sociales y políticas" (Gramsci, 2017, p. 389). 
El autor plantea que todas las personas son intelectuales, pero no todas cumplen dicha función en la sociedad. De ahí que dinstinga entre el intelectual tradicional y el orgánico. Aquí nos interesa destacar el segundo, el cual, desde el desarrollo teórico de Gramsci (2006, 2012, 2017), se puede conceptualizar como aquel que cumple una función esencial, que permite garantizar la capacidad de dirección y control de la clase dominante, representada en el bloque histórico que constituye una forma de alianza de clases.

En términos de la experiencia concreta en el campo de la intervención, esta hegemonía, reproducida por los intelectuales orgánicos, queda expresada en un tipo de política social que modela y dirige el accionar no solo en los círculos intelectuales o miembros de la clase dominante, si no como una ideología transversal, instalada y replicada en prácticamente todos los estamentos de la sociedad civil.

En tal sentido, este discurso hegemónico, que se manifiesta en el accionar de los trabajadores sociales, está determinado por el sentido común que impone la ideología dominante, y los profesionales más o menos conscientes contribuyen a su producción y reproducción, como así también a los desafíos de pensar un nuevo tipo de trabajo social (Vivero, 2013, 2017a, 2017b, 2020a, 2020b).

Sin duda, las políticas sociales sustentadas en la racionalidad neoliberal permiten que las situaciones de exclusión se mantengan, ya que los discursos y acciones tendientes a mejorar las condiciones de vida o calidad de vida de las personas están dadas por las directrices de la clase dominante. En nuestro país esto se manifiesta principalmente en el porcentaje de personas que ostenta las mayores riquezas monetarias (el $10 \%$ concentra un $66,5 \%$ del total y el $1 \%$ más acaudalado el $26,5 \%$ de la riqueza del país (CEPAL, 2017)), y que, además, se ha transformado en una fuerza política significativa, que puede mantener un sistema ideológico desplegando las estrategias necesarias para evitar su modificación o transformación.

En contraparte, en la actualidad no se han producido levantamientos o manifestaciones de los actores de la sociedad civil con la fuerza política suficiente para generar cambios estructurales e ideológicos. En 2006, con la llamada “revolución pingüina", el 2011, con las movilizaciones por la educación, el mayo feminista de 2018 y, sin duda, lo 
más relevante de las últimas tres décadas ha sido el llamado "estallido social", iniciado el 18 de octubre de 2019. Esto marca un nuevo escenario en el que el campo disciplinario debe hacer un profundo cuestionamiento a lo que ha venido desarrollando, tanto en sus espacios de intervención como en su discursividad sociopolítica (Vivero, 2013, 2017a, 2017b, 2020a, 2020b). Es decir, repensar el trabajo social desde las dimensiones histórico-políticas propias de Latinoamérica, y desde los fundamentos teóricos y metodológicos que articulan la intervención y su mirada - muchas veces acrítica- de las políticas sociales que operacionaliza.

$\mathrm{Al}$ enfocar este análisis en las políticas sociales implementadas directamente en los sectores excluidos de la sociedad civil, nos damos cuenta de que estas son construidas y diseñadas desde la perspectiva de las estructuras de poder y desde la ideología neoliberal, con un eje centralizado, estandarizado y focalizado. Por lo tanto, satisfacen necesidades que en la gran mayoría de las ocasiones no son sentidas o reconocidas como tales por los "beneficiarios", o que, por otra parte, tienden a fragmentar los beneficios para mantener la ilusión de resguardo y protección por parte del Estado.

En el contexto del retorno a la democracia, en 1990, el campo disciplinario del Trabajo Social, y particularmente en su quehacer profesional, estará orientado a responder a las lógicas de una política de Estado de carácter subsidiario, sustentado desde una racionalidad de carácter instrumental que respondería a una ética de la responsabilidad (Aguayo, 2006).

En este escenario los trabajadores sociales realizan su labor profesional; allí se convierten en ejecutores de lineamientos técnicos, en contextos en que la calidad o evaluación de resultados no es lo más relevante, sino la cantidad de atenciones comprometidas o el número de productos asociados a la intervención. Además, los profesionales son expuestos a condiciones laborales paupérrimas, que exceden muchas veces las capacidades humanas para responder las exigencias de la provisión de servicios sociales.

Lo anterior se traduce en que la labor profesional se convierta en un valor de mercado (se mercantilizan las necesidades de las personas), ya que, sin el cumplimiento de las metas comprometidas, no se 
recibirán recursos económicos para seguir la ejecución del proyecto o programa en que el profesional se desempeña, existiendo una gran tensión respecto de la perdida de la fuente laboral (Montaño, 2004).

A su vez, el profesional está centrado en la práctica, en la contingencia del día a día, ya que la mayoría de las veces debe asumir una carga laboral que sobrepasa sus capacidades, e incluso descuidando su propia salud mental y física, en el afán de cumplir y responder a las expectativas respecto de su labor. En este sentido, podemos visualizar profesionales desgastados, sobrepasados, apáticos respecto a las vivencias de los beneficiarios, lo cual se traduce en intervenciones mecanizadas, marcadas por protocolos y bases técnicas, en las que la posibilidad de construcciones conjuntas es prácticamente inexistente (Aguayo, 2007).

Desvincular la teoría de la acción es un síntoma de la dominación ideológica del capitalismo neoliberal en el campo de las ciencias sociales (Borón, 2000, 2003), por lo que el profesional, consciente o inconscientemente, reproduce las directrices o lineamientos técnicos determinados para y por el lugar en el cual desarrolla su labor.

De este modo, se convierte en un intelectual orgánico, manteniendo y replicando las estructuras que sostienen la exclusión social; adoptando, por un lado, una postura de especialista respecto a quien se dirige la acción profesional, ya que actúa en la lógica de volver a la persona y su entorno a la norma, o restituir un derecho vulnerado. $Y$, por otra parte, se ha mantenido al margen —o más bien inmóvil- en relación con una serie de situaciones atentatorias contra las libertades de las personas, así como en las luchas de reivindicaciones indígenas y campesinas, entre otras.

En relación a lo anterior, otro factor que ha influido en este rol es el imaginario que tiene la sociedad civil del quehacer del trabajador social, a quien se le atribuyen conocimientos superiores y habilidades que le permitirían abordar cualquier tipo de problemática. Su acción es vista como asistencialista mesiánica, en la cual las clases subalternas se autoidentifican como objetos pasivos de esa ayuda, dependientes de la caridad que les entregan los opresores, lo cual reproduce las lógicas de dominación (Freire, 2002, 2006).

Por otra parte, no podemos dejar de lado que el trabajador social es un sujeto con su propia historia y contexto, que se ha formado en uno 
de los tantos programas académicos del país. En este sentido, no solo pone a disposición sus conocimientos técnicos, aprendizajes y habilidades, sino también sus propios conceptos de "familia", "maternidad" y "crianza", y sus propias concepciones religiosas y de lo femenino y masculino, entre tantos otros temas que conforman las experiencias e ideologías de una persona.

En este sentido, es importante reconocer a las personas que se encuentran tras los procesos de acción profesional, ya que son ellos quienes actúan directamente con los beneficiarios; de este modo, además de cumplir con lineamientos técnicos propios de la política pública, incorporan su propia cosmovisión. Así, reproducen las ideologías de la clase dominante, ya que se encuentran inmersos en ellas, alienados por la norma y costumbre, sin mayor cuestionamiento de la existencia de saberes latinoamericanos o de pueblos originarios. Al no visualizar esta situación, es muy probable que sigan asumiendo que las personas que tienen una cosmovisión distinta se encuentran fuera del sistema, y que, por ende, es necesario "intervenir" para modificar, volver a la norma, y no para construir en conjunto.

\section{Reflexiones finales}

Es posible señalar que la labor de los trabajadores sociales se encuentra inmersa en un contexto de sociedad con una marcada hegemonía neoliberal, la que ha sido mantenida y replicada por los diferentes actores políticos desde el retorno a la democracia en 1989.

De este modo, las necesidades de las personas influenciadas por el mercado deben ser satisfechas por ellas mismas, por lo que, al no contar con recursos disponibles o las oportunidades para alcanzarlos, se encuentran excluidas del sistema, marginadas. En virtud de ello se ejecutan políticas públicas segmentadas, en pos de cubrir algunas necesidades de las personas que, en definitiva, les permitan satisfacer de manera puntual un requerimiento, pero no mejorar ostensiblemente su calidad de vida o salir de su condición de marginalidad.

Por su parte, los trabajadores sociales, a quienes históricamente se les ha atribuido un rol de gestores de cambio, puesto que actúan directamente con los miembros de la sociedad civil y, más específi- 
camente, con los que se encuentran excluidos, no han podido cumplir con este imaginario que, en definitiva, se transforma en responsabilidad. Lo anterior se puede ver reflejado en que, tras 30 años del retorno a la democracia, no se han constituido como actores políticos que puedan cuestionar al menos los modelos ideológicos de la clase dominante, generadora de la exclusión social. En cambio, se han transformado en intelectuales orgánicos: al estar en diferentes estamentos de la sociedad civil, así como en las esferas de las estructuras de poder, se han encargado de la implementación de políticas sociales mediante la ejecución de programas y proyectos, en los cuales, en su calidad de expertos, replican los lineamientos para satisfacer las necesidades de las personas, sin que exista una construcción conjunta.

Por otra parte, al volverse ejecutores de directrices elaboradas desde la clase dominante, promueven la mantención de esta ideología, lo cual puede ser consciente o inconscientemente, ya que hay que considerar que el profesional, desde el ámbito personal, se encuentra inserto en dinámicas propias de la sociedad neoliberal. A ello se debe agregar el proceso de formación, marcado por las características e ideologías de su casa de estudios.

A su vez, los distintos proyectos o programas sociales tienden a sobreexigir a los profesionales, asignándoles más carga de trabajo de la que pueden realizar, concentrando todos los esfuerzos en cumplir con las metas impuestas, lo que se traduce en atenciones o acciones estandarizadas - mecanizadas-, en las cuales los profesionales pueden llegar a normalizar situaciones o ser apáticos frente a las vivencias de las personas. Ello no lleva, a la vez, a un cuestionamiento crítico al respecto, sino solo a un estado de queja constante.

Por otro lado, es necesario revisar y reflexionar cómo los trabajadores sociales están abordando ciertas temáticas contingentes, como la parentalidad, las nuevas formas de ser familia, las concepciones de lo femenino y masculino, el divorcio, el aborto, las causas indigenistas, entre tantas otras, que están ocurriendo en lo cotidiano. Cómo las propias historias y contextos modelan al profesional más allá de los conocimientos técnicos que pueda adquirir; ser consciente de que existen temáticas que pueden ser conflictivas de abordar, por la interferencia emocional que allí subyace. 
En este sentido, se plantea un nuevo escenario para los interventores/ejecutores (profesionales e instituciones) de las políticas sociales y programas estatales, ya que el enfoque de alteridad ofrece interesantes perspectivas para el análisis y transformación de las situaciones de exclusión, dado que no sitúa el foco de la discusión únicamente en quienes sufren dichas condiciones, sino que en la sociedad en su conjunto, resignificando la sociabilidad y asignándole una responsabilidad esencial a los sujetos sobre la situación de quienes se encuentran peor situados (Rubilar, 2013, p. 209).

Finalmente, es importante reflexionar por qué el trabajador social no ha logrado convertirse en un agente de cambio, ya que es él quien se encuentra en directa relación con las bases de la sociedad civil y, a la vez, se relaciona con las estructuras de poder.

\section{Bibliografía}

Aguayo, C. (2006). Las profesiones modernas dilemas del conocimiento $y$ del poder. Santiago de Chile: Ed. UTEM.

Baraona, P. (1990). Chile en el último cuarto de siglo. Recuperado de http://www.memoriachilena.gob.cl/602/w3-article-31415. $\mathrm{html}$ \#presentacion

Borón, A. (2000). Tras el Búho de Minerva. Mercado contra democracia en el capitalismo de fin de siglo. Buenos Aires: Fondo de Cultura Económica.

Borón, A. (2003). Estado, capitalismo y democracia en América Latina. Buenos Aires: CLACSO.

Brown, W. (2015) El pueblo sin atributos. La secreta revolución del neoliberalismo. Barcelona: Editorial Malpaso.

Comisión Económica para América Latina y el Caribe (CEPAL). (2017). Estudio Económico de América Latina y el Caribe, 2017. (LC/ PUB.2017/17-P). Santiago de Chile: CEPAL.

Freire, P. (2002). Pedagogía de la esperanza. Un reencuentro con la Pedagogía del Oprimido. Buenos Aires: Siglo XXI.

Freire, P. (2006). Pedagogía del Oprimido. Buenos Aires: Siglo XXI.

Gramsci, A. (2006). Política y sociedad. Chile: Editorial Centro Gráfico.

Gramsci, A. (2012). Los intelectuales y la organización de la cultura. Buenos Aires: Nueva Visión. 
Gramsci, A. (2017). Antología. Selección, traducción y notas de Manuel Sacristán. Buenos Aires: Editorial Siglo XXI.

Montaño, C. (2004). Hacia la construcción del proyecto Ético-Político Profesional crítico. XVIII Seminario Latinoamericano de Escuelas de Trabajo Social - ALAETS

Montaño, C. (s/f). Trabajo Social e intervención: La politización de la acción profesional. Recuperado de http://www.ts.ucr.ac.cr/ binarios/pela/pl-000360.pdf

Rubilar, G. (2013). Imágenes de alteridad. Reflexiones y aportes para el trabajo social en contextos de pobreza y exclusión. Santiago de Chile: Ediciones UC.

Vivero-Arriagada, L. A. (2013). El trabajador social y su función de intelectual orgánico. Revista Regional de Trabajo Social, 27(59).

Vivero-Arriagada, L. A. (2017a). Influencia del neoliberalismo en el Trabajo Social chileno: discursos de profesionales y usuarios. Revista Colombiana de Ciencias Sociales, 8(1), 125-148. DOI: http://dx.doi.org/10.21501/22161201.1940.

Vivero-Arriagada, L. A. (2017b). Aportes del pensamiento latinoamericano al trabajo social crítico. SOPHIA AUSTRAL, 20(2), 71-81

Vivero-Arriagada, L. (2020a). Condiciones para una neo-reconceptualización del Trabajo Social en Chile, Latinoamérica y el Caribe. Prospectiva. Revista de Trabajo Social e intervención social, (29), 193-212. DOI: 10.25100/prts.v0i29.8241.

Vivero, L. (2020b). Reflexiones en torno al pensamiento de Gramsci y Freire: sus puntos de encuentro. Revista Eleuthera, 22(1), 192-211. DOI: 10.17151/eleu.2020.22.1.11. 